\title{
DEVELOPMENT AND TESTING OF ELECTRO- HYDRAULIC WAVE ENERGY SIMULATOR
}

\author{
M.A. Gomaa*, M.H Aly**, And O.E. Mahmoud***
}

\begin{abstract}
Department of Mechanical Power Engineering, Faculty of Engineering at El-Mataria, Helwan University, Massaken El-Helmia, P.O. 11718, Cairo, Egypt.

*m.abdelalim@m-eng.helwan.edu.eg,**mechhanafy@gmail.com,

***Osama_ismail@m-eng.helwan.edu.eg
\end{abstract}

\section{Abstract:}

The present work focuses on developing an experimental system that can generate mechanical simulation movement to the real waves. This developed system will facilitate the researchers within the lab testing unit for evaluating any developed point absorber WEC. Mathematical modeling, construction, and testing of ElectroHydraulic Wave Simulator that emulates different waveforms are presented. This system provides a realistic way of testing replacing the more expensive methods used to test WECs such as large indoor water tanks or real sea. A low-speed oscillation motion with higher torque is successfully produced by the developed system that is coupled to an electrical generator with a grid frequency. Finally, the model is being validated with experimental data to evaluate model accuracy, where a maximum error of $\pm 0.2 \%$ is achieved. A response time of $0.004 \mathrm{~s}$ was achieved by the valve model which matched with the manufacturer datasheet. The simulated cylinder position gives a good agreement with the measured position for a step input of $50 \mathrm{~cm}$ with a position error of less than $10 \mathrm{~mm}$.

Keywords: Hydraulic system; position control; wave energy converters; WEC; mathematical modeling; Fluid power; simulation;

\section{Introduction}

Sea and ocean waves represent higher energy density source than other renewable sources. Recent years introduces different principles of WECs Wave Energy Converters that produces electricity from wave energy. Point absorber system is one of the commonly used techniques for WEC. Most previous development depends on the theoretical study to pass over the difficulties of laboratory experimental testing of the developed WEC system. Since the 1990s, the focus on utilizing renewable alternative sources of energy instead of conventional resources has increased dramatically as a result of the global warming threat and fossil fuel reserve limitations. Wave energy, solar energy, and wind energy appears as an alternative replacement 30 years ago. The wave energy is the higher energy capacity source between these resources[1]. However, there are still many different concepts that have been established to convert the wave energy into electricity[2], such as Point absorbers, Submerged Pressure Differential, Oscillating Water Column and Overtopping device (Wavedragon), Terminator (Salter's Duck), Oscillating wave converters, Attenuator (Pelamis)[3]. 
The power of waves can be utilized for the production of electricity with various devices of WEC. The most popular one of these types is called point absorber.

Egypt experienced a consecutive crisis of fuel, and consequently electricity capacity shortages reaching its peak in 2014 according to IRENA. Also, the accelerated population growth and industrialization present an additional challenge to the limited energy resources. Therefore, the authorities focus on diversifying the electricity production sector to use different resources of renewable energy available[4].

Egypt has borders, about 3000 kilometers long, which was found to be on seacoasts. Therefore, developing suitable wave energy converter systems for real sea waves available on the Egyptian coast represents a promising solution toward many issues. It directly increases the clean and continuous energy resources available as well as generating new communities away from the highly condensed areas in Nile valley and Delta. However, the know-how of WEC systems as well as the testing facilities of the developed systems is hard to be found, especially on a laboratory scale [5]. This fact limits the development of such a system that suits the waves available on both the Mediterranean Sea and the Red Sea which has different characteristics.

Based on the available WEC system nowadays, the Mediterranean Sea has a large wave energy potential especially on the west part of the Mediterranean Sea coast lying between the Delta and Libya border at Sidi-Barrani with a potential of above 4 $\mathrm{kW} / \mathrm{m}[6]$. Hence, developing new WEC techniques could increase the usable range of Egyptian coast waves i.e. more clean energy resources. Most previous WECs studies are done theoretically because of the high cost and difficulties researchers faced in testing under real sea conditions. Using a hydraulic wave simulator tests can be done for different WECs types such as point absorber in controlled laboratory conditions, so it became an alternative testing method and needs to be enhanced. Point absorber is considered one of the simplest types of wave energy devices, which needs to be tested in a laboratory before being constructed. It contains a buoyant body moving with the waves and capture energy from waves in all directions through their movement.

Point absorber was being developed later in the 1970s and early 1980 and becomes the most popular WECs, where the oscillation of buoy is transferred into highpressure oil flowing through a motor that operates a generator to produce electricity [7]. A gas accumulator is being used to smoothen the hydraulic power to provide regular electricity production. Design and construction of wave energy extraction devices usually encountered by challenges such as:

- Irregularity of sea waves in both direction and amplitude.

- Difficulty to convert the low frequency $(0.1 \mathrm{~Hz})$ irregular motion into uniform frequency electricity that fits with grid network characteristics. 
- Shortage of laboratory testing i.e. offshore testing facilities of WEC systems [8].

To overcome these difficulties, a model of a laboratory testing facility was developed with scale (1:5) based on a hydraulic system to generate wave simulation motion of both frequency and amplitude of real ones. This facility focuses on testing PTOs systems for their advantages to deal with low frequency, high force wave inputs.

Previous WECs model testing was performed at 1:80 to 1:25 scales in non-large tanks. Then testing was done in the deepest and largest indoor water tanks at a scale of $1: 10$. But these scales are small for accurate modeling and testing. Consistent with Froude's law, at a 1:10 scale, the power scale is 1:3162. Therefore, if a WEC with a power of $1000 \mathrm{~kW}$ being simulated using tank tests, then the output power would be $0.32 \mathrm{~kW}$. As the simulated power is small then the simulation at these scales will not be accurate enough. Subsequently, the device would need to be tested at a 1:5 scale or larger [8].

However, testing can be done in a laboratory at an adequate scale using a hydraulic cylinder that directly moves the PTO, as the 1:7 and full-scale tests performed in the Pelamis device [9]. This method provides another testing way in the laboratory employing a relatively cheap wave simulator test bench at a suitable scale that can reach 1:4, avoiding usage of large wave tanks or real sea-waves testing.

The present research aims to develop robust mathematical modeling of electrohydraulic (EHA) wave simulator based on piston position controlling. The model was obtained under the MATLAB/SIMULINK software environment. The electrohydraulic system has significant non-linear behavior due to fluid characteristics and complex flow properties of the used proportional valve. Various parameters are controlling the performance of the hydraulic system. Some of these parameters can be obtained from the manufacturer's datasheets while the others are determined by laboratory measurements using system identification. Where the electrohydraulic system needs to perfectly simulate real sea waves and minimize cylinder position error as possible. Different position controllers for EHA systems have been applied by various researchers. A robust electro-hydraulic position control scheme using sliding mode control was proposed in [10].

Other proposed position control methods such as the use of proportional integral differential control, pole placement technique, feedback linearization method to cancel nonlinearities in the system [11], "modified backstepping control with an iterative learning mechanism to perform adaptive tracking control tasks, and perfect tracking optimal control by adopting a combination of feedback and feedforward controller [12]. 
In this paper, the mathematical modeling, construction, and testing of a Hydraulic Wave Simulator that emulates the different incoming Waves to energy capture devices are presented.

\section{Hydraulic Wave Simulator System Description}

Testing of WECs using hydraulics wave simulator system for its capability to produce slow, high force motion similarly to actual sea waves.

In the developed model, the PTO load force is simulated by a combination of damping and spring force. Currently, it's hard to find a standard design for industrial hydraulic PTO while some companies use a simple system with limited energy storage to drive a variable speed generator. Other companies develop a more complex hydraulic system with energy storage integrated to drive a synchronous generator.

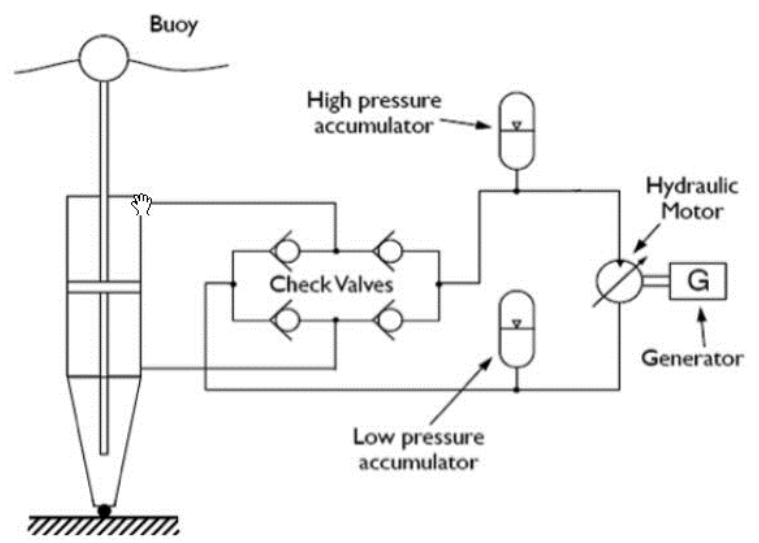

Figure 1. Typical hydraulic PTO with energy storage.

The vertical oscillation motion of the buoy lying on the water surface is being converted into a one-way flow of oil using four non-return valves that rectify the flow exit from the cylinder to ensure a single motor rotation direction. Therefore, the motor could be coupled to a DC generator to produce electricity, as shown in Figure 1 [9].

In the present research, Wave energy converters and Power Takeoff devices are presented. Egypt wave energy potential is discussed especially at Mediterranean Sea coasts that give the promising capacity. Then going through the testing history of wave energy devices and difficulties researchers found that obstacle wave devices development.

Laboratory constructed Wave simulator that consists of a hydraulic cylinder and the proportional valve is investigated in terms of their behavior and mathematical models so can be used in Simulation using MATLAB Simulink Toolbox. The wave simulator model is being produced that simulates the real experimental test rig. Finally, the model is being validated with a real system that researchers can use in future testing studies of different sea states and different PTO devices. 


\section{Mathematical Modeling and Simulation of Electro-Hydraulic Wave Simulator}

The governing mathematical equations have been studied to describe the operation of the electrohydraulic Wave Simulator. These equations have been integrated into SIMULINK software to predict real system behavior. The parameters required in the simulation are obtained by the manufacturer's data sheets and experimental measurement.

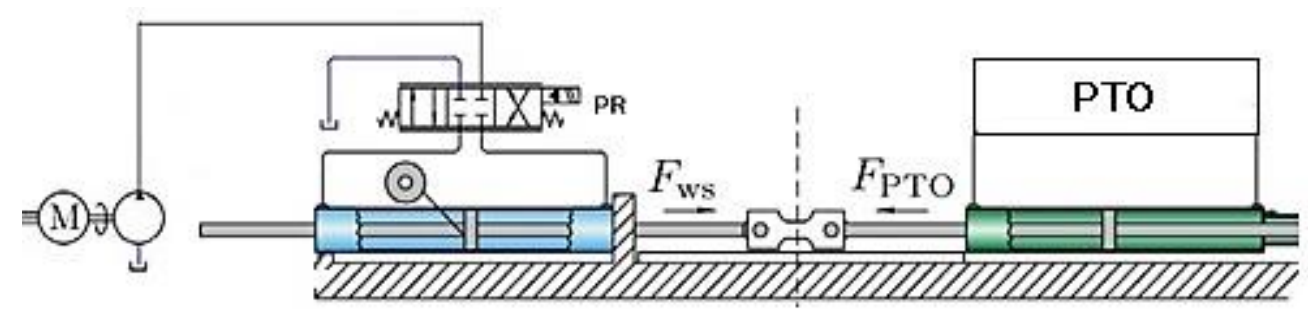

Figure 2. Wave energy simulator and PTO

Two symmetric double rod actuators controlled by a four-way proportional valve were used to represent the buoy motion in a closed-loop system, as shown in Figure 2. The left actuator generates the force results from the Sea wave, while the right one is the load or actuator used to extract the power of the wave, in a PTO system. The effect of pipelines was neglected to simplify the modeling process. Besides, the auxiliary components of the hydraulic system were neglected and only the valve and cylinder were considered in the modeling process as shown in Figure 3. The effects of compressibility, internal leakage, and inertia are considered in the mathematical model to extend model accuracy. After the mathematical model had been obtained, the nonlinear model was developed using the MATLAB/ SIMULINK software.

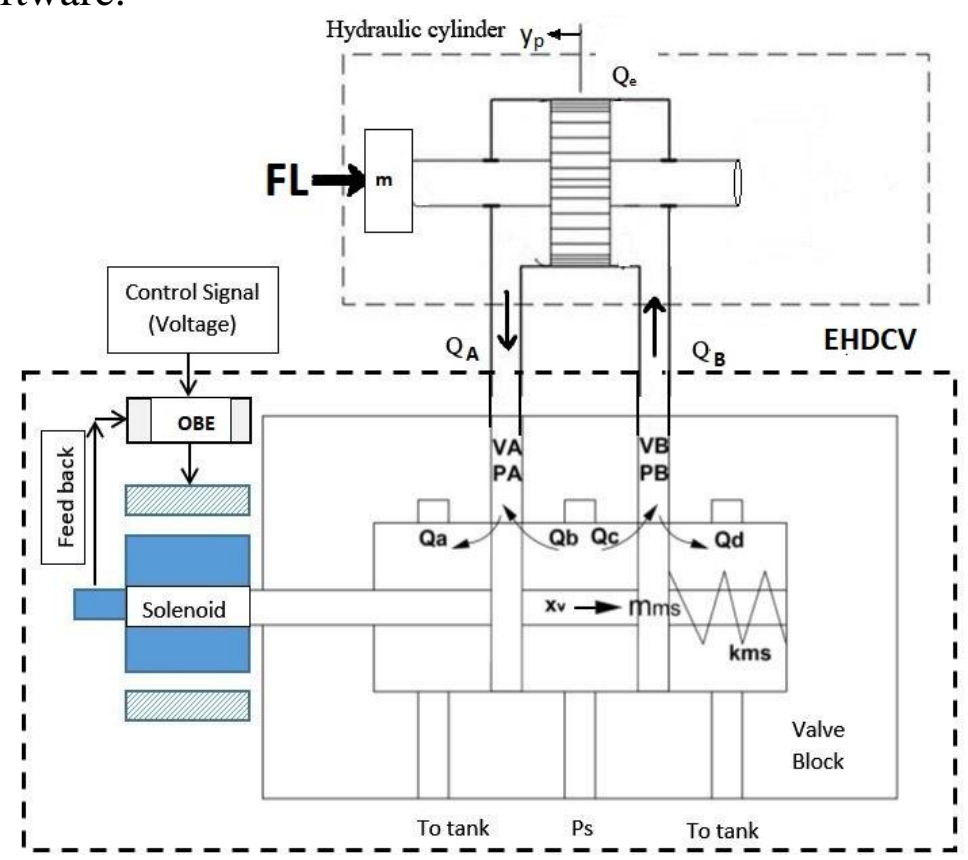

Figure 3. Schematic of valve-cylinder combination 


\subsection{Proportional Valve Model}

Proportional valves are used in cylinder position control applications, where it could control both flow rate and direction, in addition to the valve's easy operation characteristics. The utilized proportional control valve is Rexroth 4WRPEH6 with on-board electronics (OBE). Proportional valve parameters values may be known with acceptable accuracy or only identified within a certain range, and other parameters are completely unknown. This may be due to manufacturing tolerances, or because parameter values don't be given by manufacturers, because they consider them as proprietary information [13]. Such missing parameters can be chosen or adjusted in the model to fit the behavior of the real system.

The Valve model consists of:

- Valve dynamics subsystem

- Orifices flow subsystem.

A second-order model for the proportional valve was developed based on datasheet data and tests done on the valve. Both the valve Spool and the feedback OBE sensor can be represented as a first-order system so the overall closed-loop transfer function of the proportional solenoid can be approximated as a linear model of the second-order as seen in [14] as shown in Figure 4. The dynamic behavior of the electromechanical converter and the spool valve can be identified with a linear second-order model between the reference volt $\mathrm{V}_{\text {ref }}$ and the slide valve position $\mathrm{X}_{\mathrm{v}}$, as indicated in equation (1)

$$
\frac{X_{\mathrm{V}}}{V_{\text {ref }}}=\frac{\mathrm{k}_{\mathrm{s}} * \omega_{\mathrm{n}}{ }^{2}}{\mathrm{~S}^{2}+2 * \zeta * \omega_{\mathrm{n}} * \mathrm{~S}+\omega_{\mathrm{n}}{ }^{2}}
$$

Where $\mathrm{k}_{\mathrm{S}}(\mathrm{m} / \mathrm{V})$ is the static gain of the valve, $\zeta$ is the valve's damping factor, and $\omega_{\mathrm{n}}(\mathrm{rad} / \mathrm{s})$ is the valve's natural frequency.

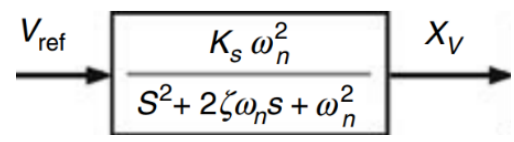

Figure 4. Block diagram of the valve electromechanical converter and the spool.

The input voltage to the proportional solenoid changes the spool position, therefore changes the size of the flow areas through the valve orifices. The regulated flow can be described by the general equation of flow through the orifice given in Equation (2), refer to Figure 5.

$$
\mathrm{Q}_{i}=\mathrm{C}_{\mathrm{d}} A_{i} \sqrt{2\left(\mathrm{P}_{1}-\mathrm{P}_{2}\right) / \rho}
$$

Based on the proportional valve geometry, the flow through the valve restriction areas expressed as a function of the pressures are given in Equations (3), (4), (5), and (6).

$$
\begin{aligned}
& \mathrm{Q}_{\mathrm{a}}=\mathrm{C}_{\mathrm{d}} \mathrm{A}_{\mathrm{a}(X)} \sqrt{2\left(\mathrm{P}_{\mathrm{A}}-\mathrm{P}_{\mathrm{t}}\right) / \rho} \\
& \mathrm{Q}_{\mathrm{b}}=\mathrm{C}_{\mathrm{d}} \mathrm{A}_{\mathrm{b}(X)} \sqrt{2\left(\mathrm{P}_{\mathrm{s}}-\mathrm{P}_{\mathrm{t}}\right) / \rho}
\end{aligned}
$$




$$
\begin{aligned}
& \mathrm{Q}_{\mathrm{c}}=\mathrm{C}_{\mathrm{d}} \mathrm{A}_{\left.\mathrm{c}_{(X)}\right)} \sqrt{2\left(\mathrm{P}_{\mathrm{s}}-\mathrm{P}_{\mathrm{t}}\right) / \rho} \\
& \mathrm{Q}_{\mathrm{d}}=\mathrm{C}_{\mathrm{d}} \mathrm{A}_{\mathrm{d}_{(X)}} \sqrt{2\left(\mathrm{P}_{\mathrm{B}}-\mathrm{P}_{\mathrm{t}}\right) / \rho}
\end{aligned}
$$

The flow rates $Q_{A}$ and $Q_{B}$ are given by

$$
\begin{aligned}
& \mathrm{Q}_{A}=\mathrm{Q}_{\mathrm{a}}-\mathrm{Q}_{\mathrm{b}} \\
& \mathrm{Q}_{\mathrm{B}}=\mathrm{Q}_{\mathrm{c}}-\mathrm{Q}_{\mathrm{d}}
\end{aligned}
$$

Where $Q_{a}, Q_{b}, Q_{c}$, and $Q_{d}$ are the flow rates through valve opening $A_{a}, A_{b}, A_{c}, A_{d}$ $\left[\mathrm{m}^{3} / \mathrm{s}\right]$ respectively.

$\mathrm{P}_{\mathrm{S}}=$ Supply pressure $\mathrm{Pa}$,

$\mathrm{P}_{t}=$ The pressure of the discharge reservoir, $\mathrm{Pa}$

$\mathrm{P}_{\mathrm{s}}, \mathrm{P}_{\mathrm{B}}=$ Supply pressure and Return pressure, $\mathrm{Pa}$

$A_{a}, A_{b}, A_{c}, A_{d}=$ the valve flow areas through openings $a, b, c, d$ respectively, $\mathrm{m}^{2}$ $\mathrm{x}=$ Spool valve opening distance, $\mathrm{m}$

$\mathrm{C}_{\mathrm{d}}=$ Discharge coefficient which is the same for all ports.

The flow areas $A_{a}, A_{b}, A_{c}, A_{d}$, are functions of the spool displacement $X_{V}$, where the length of the total spool stroke is small as shown in Figure 5.

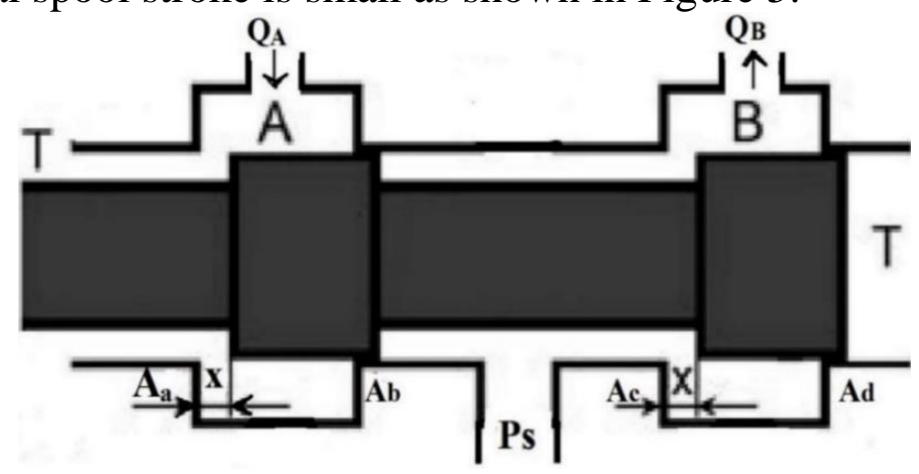

Figure 5. Oil flow rates through the proportional valve

Hydraulic valves have different design shapes of ports open that affect the flow paths from $\mathrm{P}$ to $\mathrm{B}$ and $\mathrm{A}$ to $\mathrm{T}$, therefore, accurate modeling should take the real shape into account. Equations (9), (10), and (11) show the flow areas taking the real valve orifices shape as shown in Figure 6. 


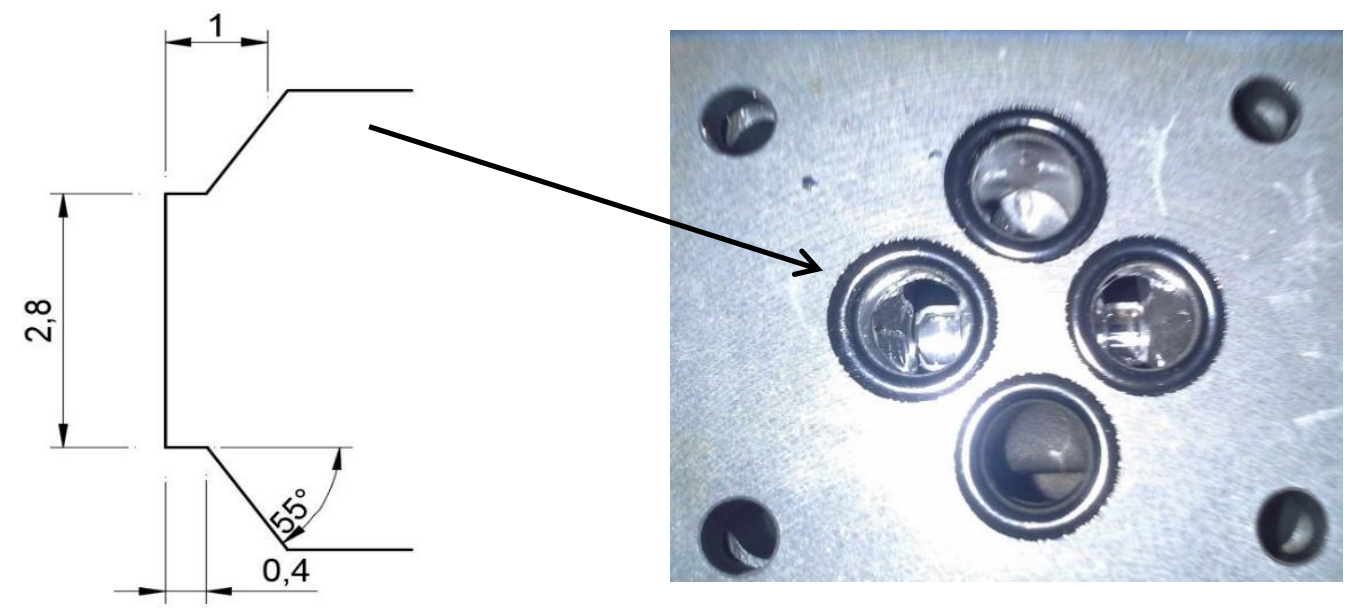

Figure 6. Valve flow areas (dimensions in $\mathbf{m m}$ )

The throttling area is simply calculated by the following formulas.

$$
\begin{gathered}
A_{\mathrm{a}}=\mathrm{A}_{\mathrm{c}}=\left(\begin{array}{cc}
\mathrm{x}_{\mathrm{V}} * 2.8 & 0.0<\mathrm{x}_{\mathrm{v}}<0.4 \\
\mathrm{x}_{\mathrm{v}} * 2.8+\mathrm{x}_{\mathrm{v}}{ }^{2} \tan \left(55^{\circ}\right) & 0.4 \leq \mathrm{x}_{\mathrm{V}}<1 \\
\mathrm{r} & \mathrm{x} \leq 0.0
\end{array}\right) \\
\mathrm{A}_{\mathrm{b}}=\mathrm{A}_{\mathrm{d}}=\left(\begin{array}{cc}
\mathrm{r} & \mathrm{x}_{\mathrm{V}} \geq 0 \\
\mathrm{x}_{\mathrm{v}} * 2.8 & 0.0>\mathrm{x}_{\mathrm{V}}>-0.4 \\
\mathrm{x}_{\mathrm{v}} * 2.8+\mathrm{x}_{\mathrm{v}}{ }^{2} \tan \left(55^{\circ}\right) & -0.4 \geq \mathrm{x}_{\mathrm{v}}>-1.0
\end{array}\right) \\
\mathrm{r}=\pi * \mathrm{~d}_{\mathrm{s}} * \mathrm{clr}
\end{gathered}
$$

Where $A$ is radial clearance area $\left[\mathrm{mm}^{2}\right], r$ is radial clearance $[\mathrm{mm}]$ and $\mathrm{d}_{\mathrm{s}}$ is the main spool diameter [mm]

The valve discharge coefficient can be obtained from experimental tests, otherwise can be obtained from some calculations done using some parameters from the manufacturer datasheet $\left(\mathrm{x}_{\mathrm{v}}, \mathrm{Q}_{\mathrm{n}}\right.$, and $\left.\Delta \mathrm{p}_{\mathrm{n}}\right)$ [13]. where $\mathrm{x}_{\mathrm{v}}$ the valve maximum stroke, $\mathrm{Qn}$ is the valve nominal flow, and $\Delta \mathrm{p}_{\mathrm{n}}$ the valve nominal pressure drop. Then the more practical way to determine the corresponding discharge coefficient $C_{d}$ according to Equation 12.

$\rho=$ Oil density, $\mathrm{kg} / \mathrm{m}^{3}$

$$
\mathrm{C}_{\mathrm{d}}=\frac{\mathrm{Q}_{\mathrm{N}}}{\mathrm{A}_{(\mathrm{Xv}, \max )} \sqrt{\Delta \mathrm{p}_{\mathrm{N}} / \rho}}
$$

Discharge coefficient is found to be: $C_{d}=0.678$ 
Where the control input $\mathrm{V}$ of the proportional valve causes the spool to move then controls the flow between the valve ports. Oil is supplied with a constant supply pressure $\mathrm{P}_{\mathrm{s}}$ and the oil returns under the atmospheric pressure $\mathrm{P}_{\mathrm{t}}$ to the tank.

Using equations (1) to (12), a block diagram has been developed for the proportional valve subsystem in MATLAB-Simulink as shown in Figure 7. MATLAB-Simulink allows simulation of very complex systems and solving equations numerically with a graphical user interface. MATLAB-Simulink is suitable for modeling and visualizing methods such as closed loops, analysis of data, and production of figures with good quality. Simulink blocks can contain variables, where variables are required to be defined in the workspace window.

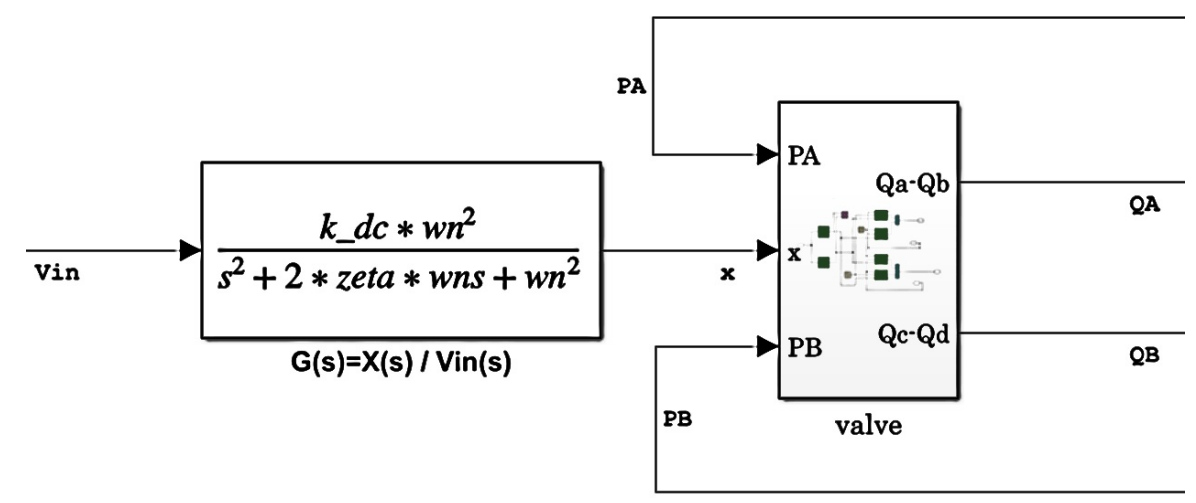

Figure 7. Total block diagram of the proportional valve subsystems.

The detailed valve model is shown in Figure 8, while the valve flow area model is shown in Figure 9, and flowrates through valve openings being modeled are shown in Figure 10.

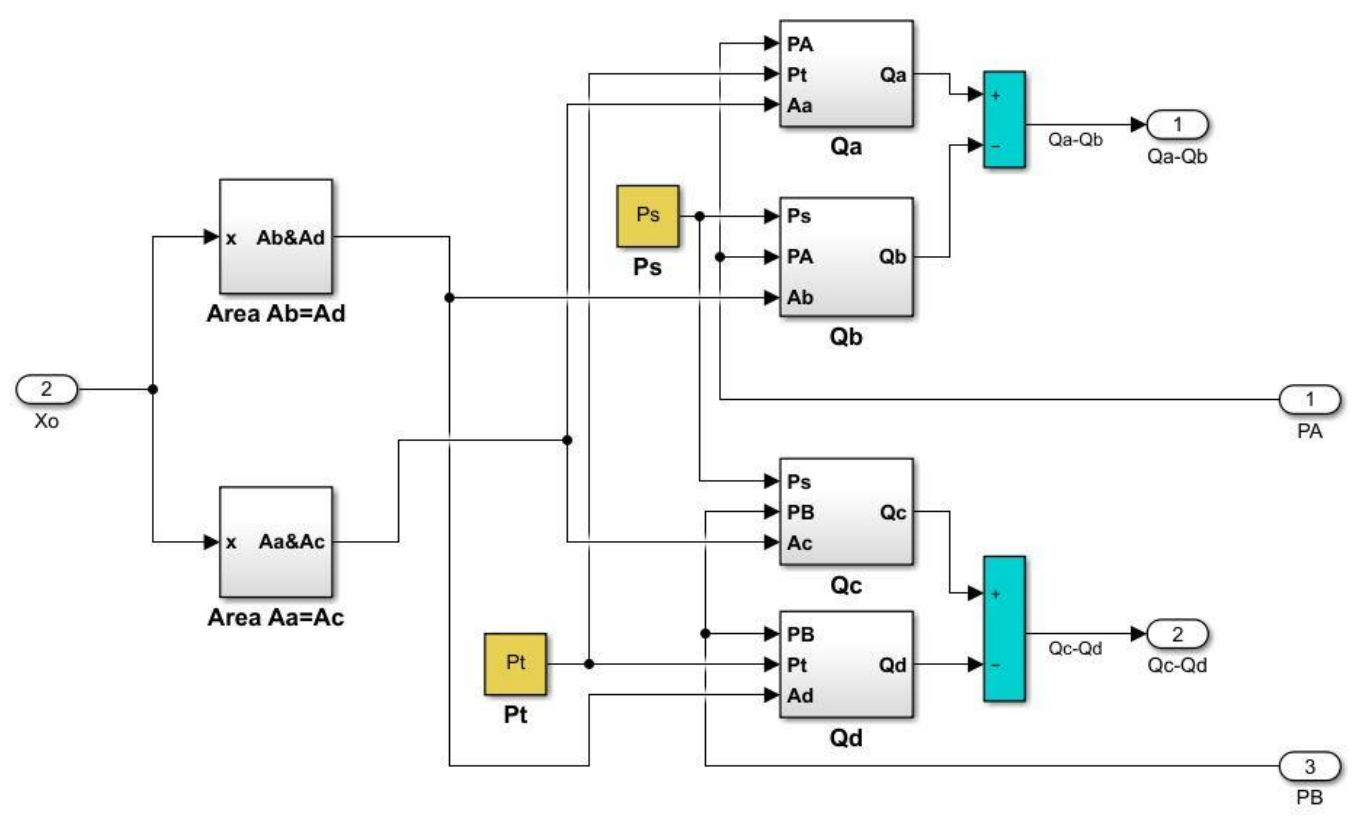

Figure 8. Detailed valve model 


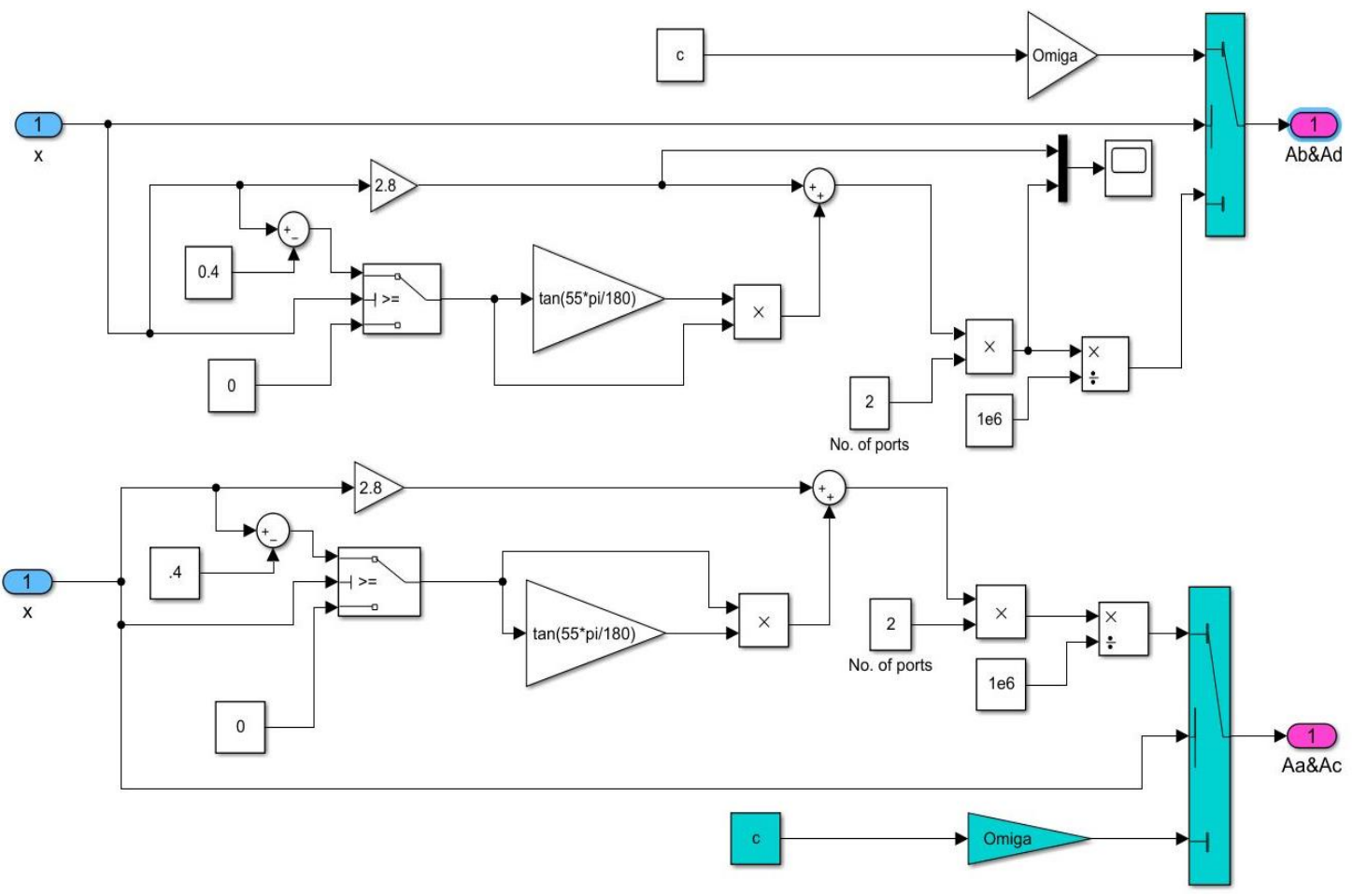

Figure 9. Detailed valve flow areas subsystem

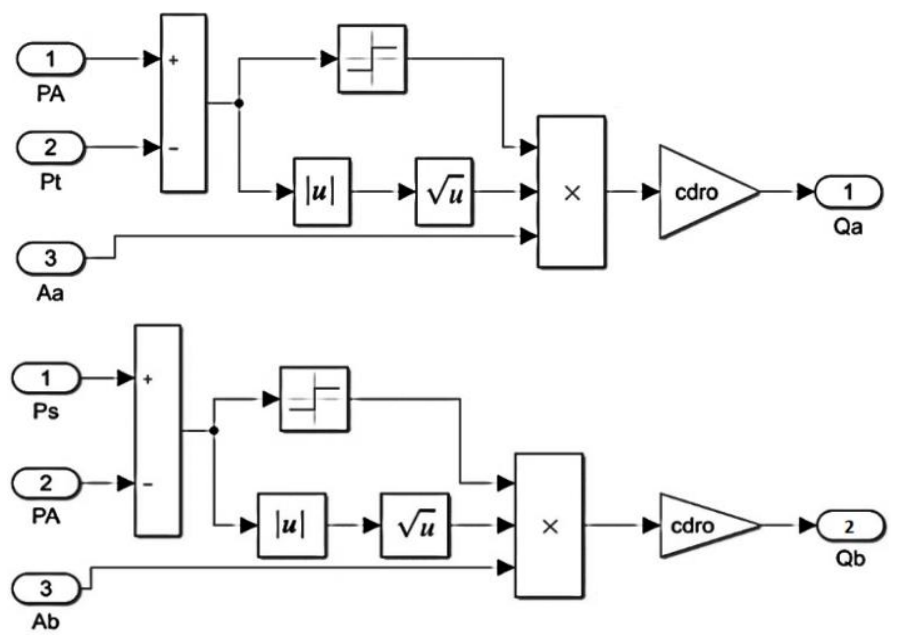

Figure 10. Detailed valve openings flow rates

\subsection{Modeling of Hydraulic Cylinders:}

Modeling of the cylinder refers to determining the chamber pressure and the motion of the piston in the cylinder. The continuity equations for compressible fluids are used to express the pressures and the motion of the actuator is being modeled by Newton's second law of motion.

Then the hydraulic cylinder model requires:

- The pressure dynamic model

- The load equation model 


\subsubsection{Applying Continuity Equation to the Cylinder Chambers:}

The actuator is modeled by using the continuity equations in the cylinder chambers and the dynamic equilibrium equation for the rod.

The continuity equation is expressed in a general form:

$$
\rho\left(\sum \mathrm{Q}_{\text {in }}-\sum \mathrm{Q}_{\text {out }}\right)=\frac{\mathrm{d}(\rho \mathrm{V})}{\mathrm{dt}}=\rho \frac{\mathrm{dV}}{\mathrm{dt}}+\mathrm{V} \frac{\mathrm{d} \rho}{\mathrm{dt}}
$$

Where

$$
\begin{aligned}
& \sum Q_{\text {in }}=\text { sum of the flows in volume entering the cylinder } \\
& \sum Q_{\text {out }}=\text { sum of the flows in volume leaving the cylinder } \\
& \rho=\text { density } \\
& V=\text { total oil volume in the cylinder, } \mathrm{m}^{3} \\
& \mathrm{t}=\text { time }
\end{aligned}
$$

From the definition of the compressibility modulus of oil $\beta$, and $\mathrm{P}$ is the pressure in the chamber considered [15]:

$$
\frac{d V}{V}=-\frac{d \rho}{\rho}=-\frac{d p}{\beta}
$$

We get

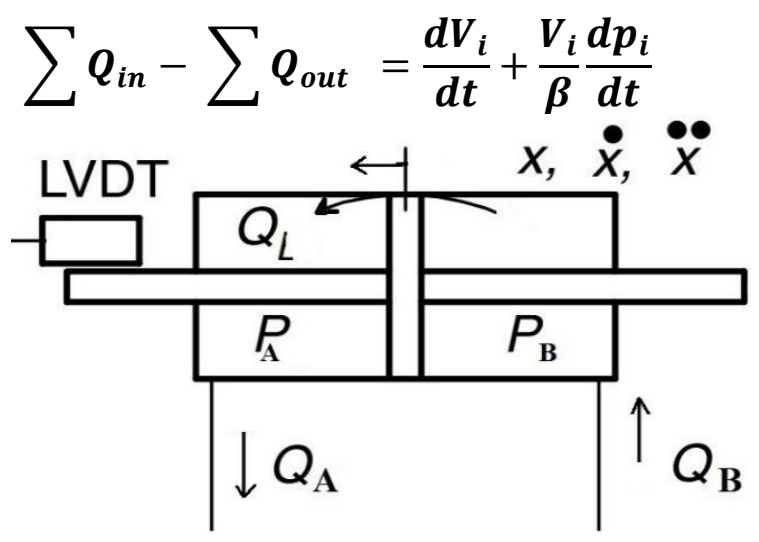

Figure 11. Double rod cylinder

Applying the continuity equation for the right chamber shown in Figure 11 yields the following equations:

Where

$$
\begin{aligned}
& \sum Q_{\text {in }}-\sum Q_{\text {out }}=\frac{\mathrm{dV}_{B}}{\mathrm{dt}}+\frac{\mathrm{V}_{B}}{\beta} \frac{\mathrm{d} p_{B}}{\mathrm{dt}} \\
& \sum Q_{\text {in }}-\sum Q_{\text {out }}-\frac{d V_{B}}{d t}=\frac{V_{B}}{\beta} \frac{d p_{B}}{d t}
\end{aligned}
$$




$$
\begin{gathered}
\mathrm{V}_{B}=\mathrm{V}_{O}+\mathrm{A}_{\mathrm{p}} \mathrm{y} \\
\mathrm{Q}_{\mathrm{B}}-\mathrm{A}_{\mathrm{p}} \frac{\mathrm{dy}}{\mathrm{dt}}-\mathrm{Q}_{\mathrm{li}}-\mathrm{Q}_{\mathrm{leB}}=\frac{\mathrm{Vo}_{\mathrm{o}}+\mathrm{A}_{\mathrm{p}} \mathrm{y}}{\beta} \frac{\mathrm{dP}_{\mathrm{B}}}{\mathrm{dt}}
\end{gathered}
$$

Applying the continuity equation for the left chamber yields the following equation:

$$
\begin{gathered}
\sum \mathrm{Q}_{\mathrm{in}}-\sum \mathrm{Q}_{\text {out }}+\frac{\mathrm{dV}_{\mathrm{A}}}{\mathrm{dt}}=\frac{\mathrm{V}_{\mathrm{A}}}{\beta} \frac{\mathrm{dp}_{\mathrm{A}}}{\mathrm{dt}} \\
\mathrm{Q}_{\mathrm{li}}+\mathrm{A}_{\mathrm{p}} \frac{\mathrm{dy}}{\mathrm{dt}}-\mathrm{Q}_{\mathrm{A}}-\mathrm{Q}_{\mathrm{leA}}=\frac{\mathrm{Vo}_{\mathrm{o}}-\mathrm{A}_{\mathrm{p}} \mathrm{y}}{\beta} \frac{\mathrm{dP}_{A}}{\mathrm{dt}}
\end{gathered}
$$

Where

$$
\mathrm{V}_{\mathrm{A}}=\mathrm{V}_{\mathrm{O}}-\mathrm{A}_{\mathrm{p}} \mathrm{y}
$$

The flow rates $Q_{A}$ and $Q_{B}$ are given by

$$
\begin{aligned}
& \mathrm{Q}_{A}=\mathrm{Q}_{\mathrm{a}}-\mathrm{Q}_{\mathrm{b}} \\
& \mathrm{Q}_{\mathrm{B}}=\mathrm{Q}_{\mathrm{c}}-\mathrm{Q}_{\mathrm{d}}
\end{aligned}
$$

The flow rate of leakage is assumed to be linearly proportional to the pressure difference;

The leakage flow rates are given by:

Where

$$
\begin{gathered}
\mathrm{Q}_{\mathrm{li}}=\left(\mathrm{P}_{\mathrm{B}}-\mathrm{P}_{\mathrm{A}}\right) / \mathrm{R}_{\mathrm{i}} \\
\mathrm{Q}_{\mathrm{leB}}=\mathrm{P}_{\mathrm{B}} / \mathrm{R}_{\mathrm{e} 1} \\
\mathrm{Q}_{\mathrm{leA}}=\mathrm{P}_{\mathrm{A}} / \mathrm{R}_{\mathrm{e} 2}
\end{gathered}
$$

$\mathrm{V}_{\mathrm{o}}=$ Half of oil volume filling the cylinder, $\mathrm{m}^{3}$

$\mathrm{Q}_{\mathrm{e} 1,2}=$ External leakage flow rate, $\mathrm{m}^{3} / \mathrm{s}$

$\mathrm{Q}_{\mathrm{li}}=$ Internal leakage flow rate represents the oil leakage flow between the piston and the barrel., $\mathrm{m}^{3} / \mathrm{s}$

$\mathrm{Re}=$ Resistance to oil external leakage, $\mathrm{Pa} . \mathrm{s} / \mathrm{m}^{3}$

$\mathrm{Ri}=$ Resistance to oil internal leakage, $\mathrm{Pa} . \mathrm{s} / \mathrm{m}^{3}$

The pressures $P_{A}$ and $P_{B}$ are determined by the oil flow rates $Q_{A}$ and $Q_{B}$ entering and leaving the chambers.

\subsubsection{Equation of Piston Motion}

By applying Newton's second law to the piston forces, the piston equation of motion can be calculated. 
The $y$ position of the piston is determined by the equilibrium of the forces acting on it: external force, thrust due to the pressures $\mathrm{P}_{1}$ and $\mathrm{P}_{2}$ acting in the chambers of the cylinder, force of inertia, and friction force.

The dynamic equilibrium equation of the piston is:

$$
A_{p}\left(P_{B}-P_{A}\right)=m \frac{d^{2} y}{d t^{2}}+f_{v} \frac{d y}{d t}+F_{L}
$$

Where

$\mathrm{y}=$ piston displacement $[\mathrm{cm}]$

$\mathrm{A}_{\mathrm{p}}=$ Piston area, $\left[\mathrm{m}^{2}\right]$

$\mathrm{m}=$ moving parts mass $[\mathrm{kg}]$

$\mathrm{f}_{\mathrm{v}}=$ Friction coefficient, $[\mathrm{Ns} / \mathrm{m}]$

$\mathrm{F}_{\mathrm{L}}=$ Loading force, $[\mathrm{N}]$

The piston is being driven by the oil entering QA and the leaving oil QB, so pressures PA and PB are generated moving the mass of the cylinder.

Model subsystems shown in Figures 12,13 and 14 are combined to form the hydraulic cylinder total block diagram as shown in Figure 15.

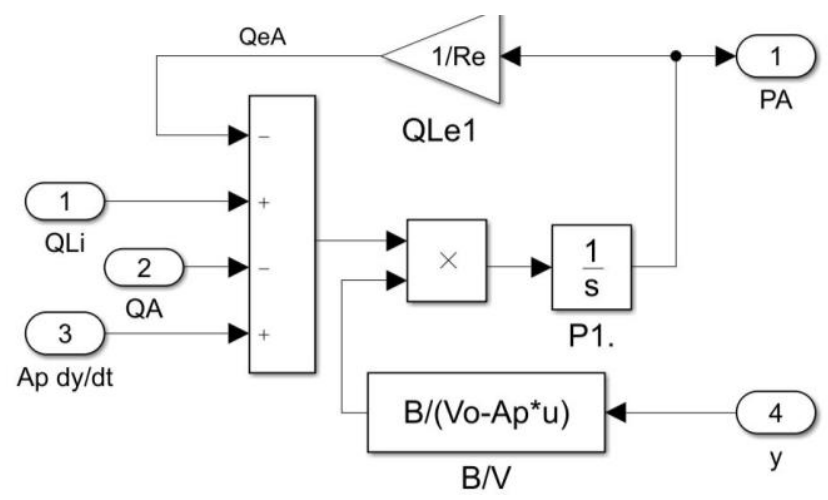

Figure 12. Pressure dynamics for chamber (A)

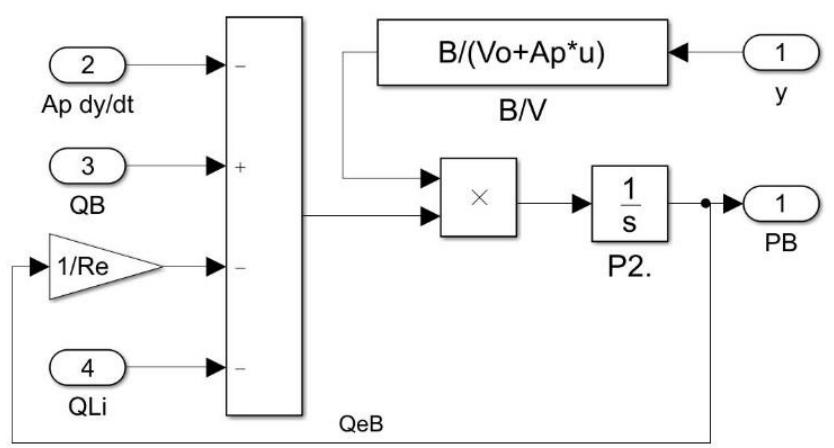

Figure 13. Pressure dynamics for chamber $(B)$ 


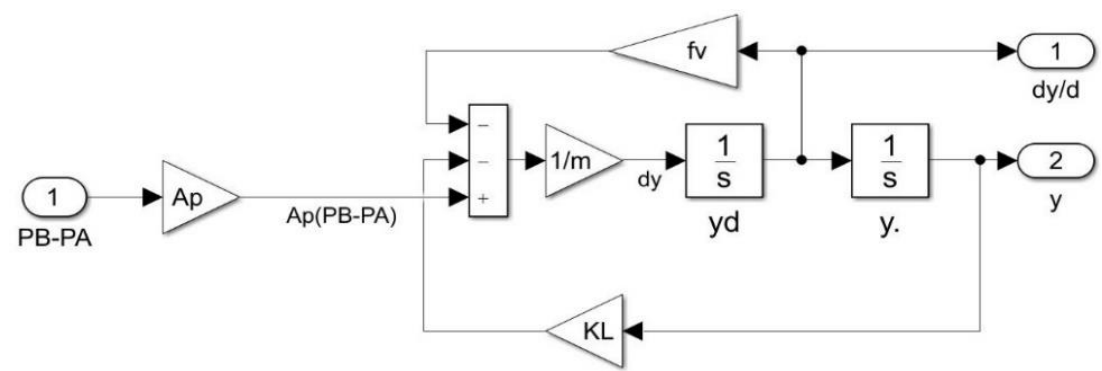

Figure 14. Piston equation of motion

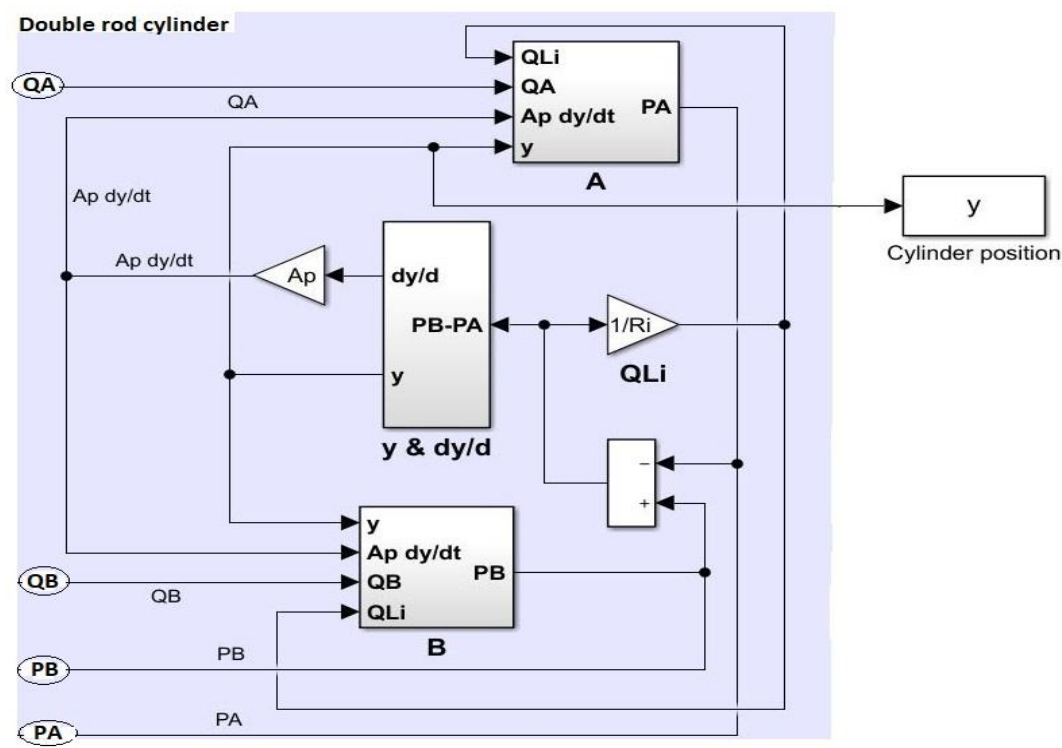

Figure 15. Total block diagram of double rod cylinder

By combining all the models of the valve and actuator subsystems, the total SIMULINK block diagram of EHA can be obtained as shown in Figure 16.

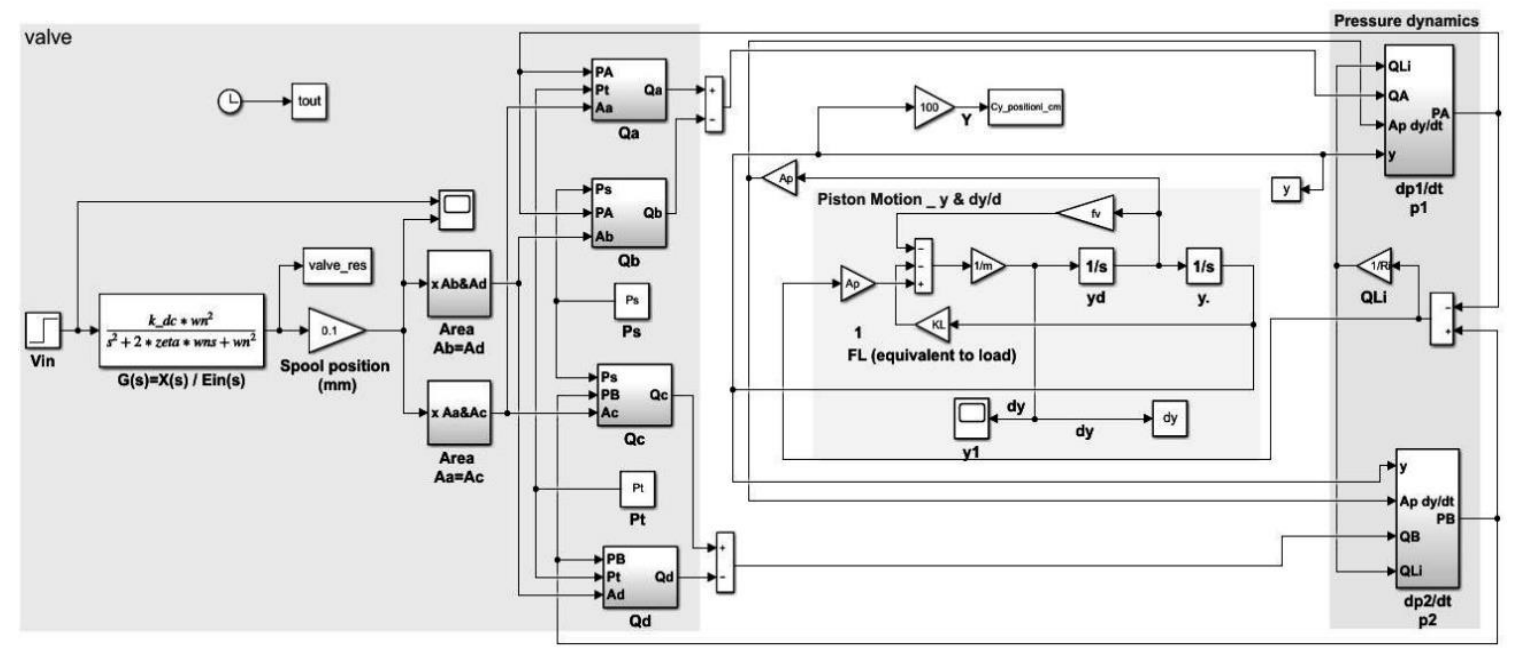

Figure 16. Hydraulic system complete model 


\section{Experimental Setup}

The experimental EHA real-time photo is shown in Figure 17. The system consists of a power unit that contains an oil tank with a volume of 225 liters, a relief valve, a sight glass, a strainer, a filter, and an electric motor of $15 \mathrm{HP}$ at $1450 \mathrm{rpm}$.

The selected gear pump has $16 \mathrm{~cm}^{3} / \mathrm{rev}$ equivalent to $24 \mathrm{~L} / \mathrm{min}$ and is driven by a three-phase electrical motor $15 \mathrm{HP}$.

The oil direction is being controlled by the proportional valve of type Bosch Rexroth size 6, 4/3 with max. flow rate: $24 \mathrm{~L} / \mathrm{min}$. The two double rod cylinders are connected. The oil enters a double rod cylinder of $50 \mathrm{~cm}$ total stroke with a $30 \mathrm{~mm}$ rod and a $50 \mathrm{~mm}$ bore diameter.

The piston position sensor is a linear potentiometer (LPT) type OPKON which ranged from 0 to $75 \mathrm{~cm}$. The sensor end is being fixed to the piston rod, as shown in Figure 17. The input signal was done by DAQ-6036E and signals are acquired by NI PCI/PXI-6220 from National Instruments and then they are sent to the PC with operating system Windows XP.

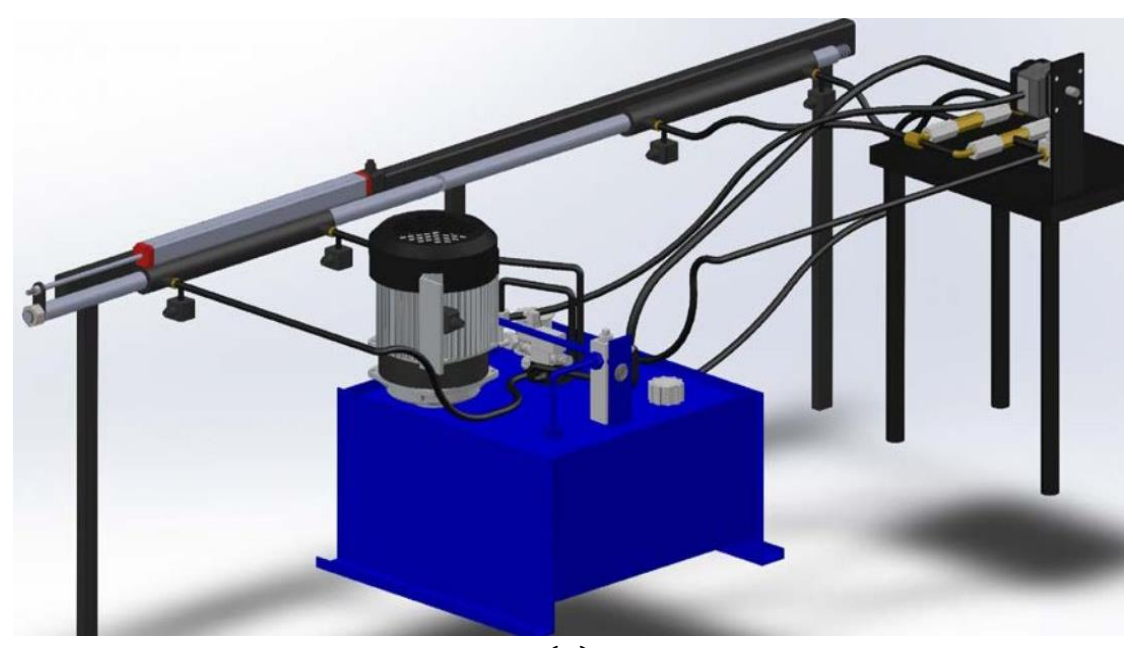

(a)

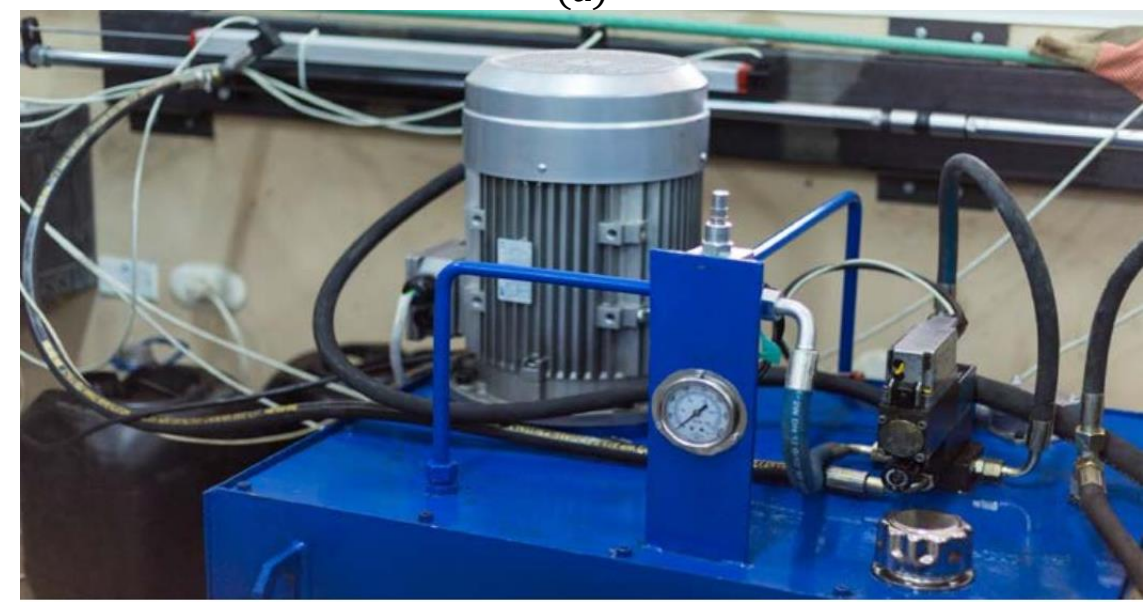

(b)

Figure 17. A real-time picture of the wave simulator (a) and (b) 


\section{Results and Discussion}

Experiments are performed to validate the proportional valve performance. The proportional valve response is evaluated, where the valve has a spool position feedback measured by valve LVDT.

Giving the valve a step input of 5 voltages, the valve opens and directs flow to the cylinder. Figure 18 shows the valve input voltage and measured valve feedback voltage signal, which shows that the valve response is high with a response time of $0.004 \mathrm{sec}$ with peak percentage overshoot $(15 \%)$ which is acceptable.

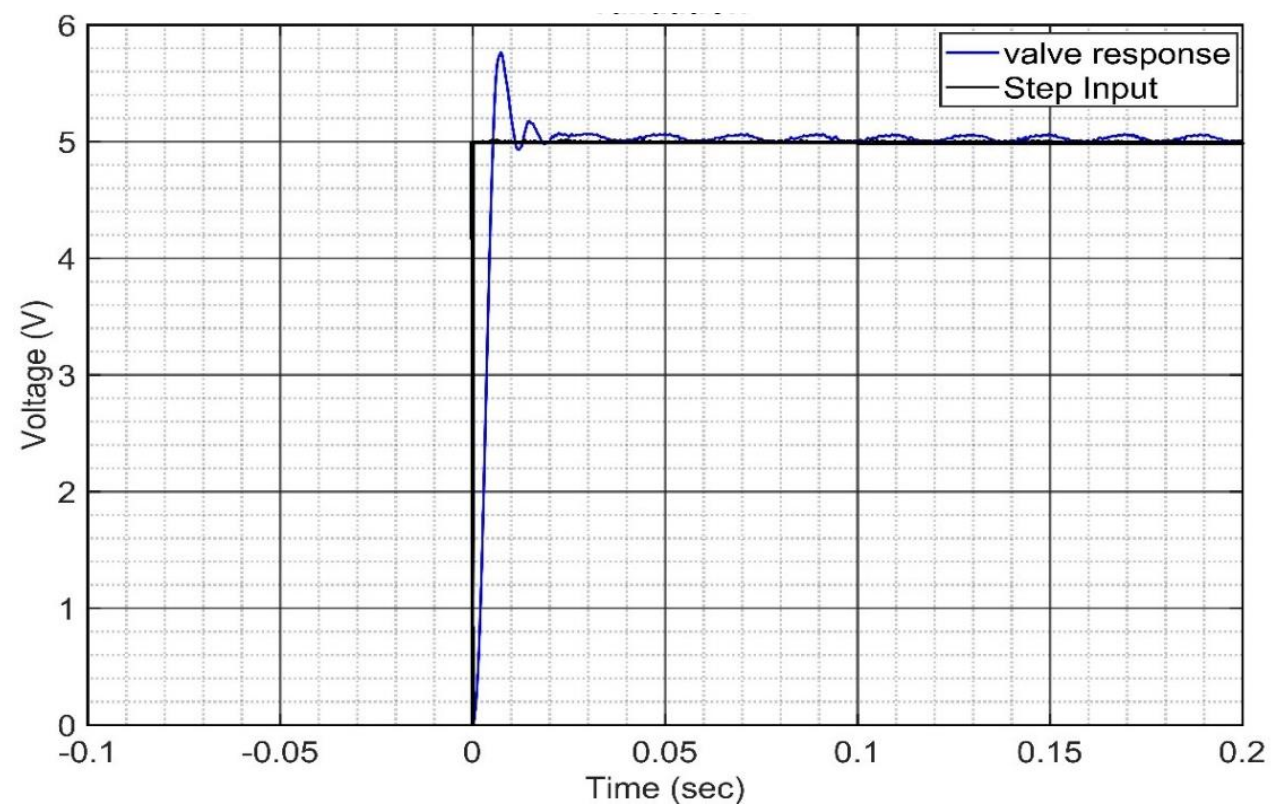

Figure 18. Step input model valve response

Figure 19 shows valve validation between simulated valve spool position in voltage and the experimental feedback signal from LVDT in voltage. It can be noticed that simulation gives dynamic similarity with real valve. The valve response time is found less than $10 \mathrm{~ms}$ which is matched with valve datasheet characteristics.

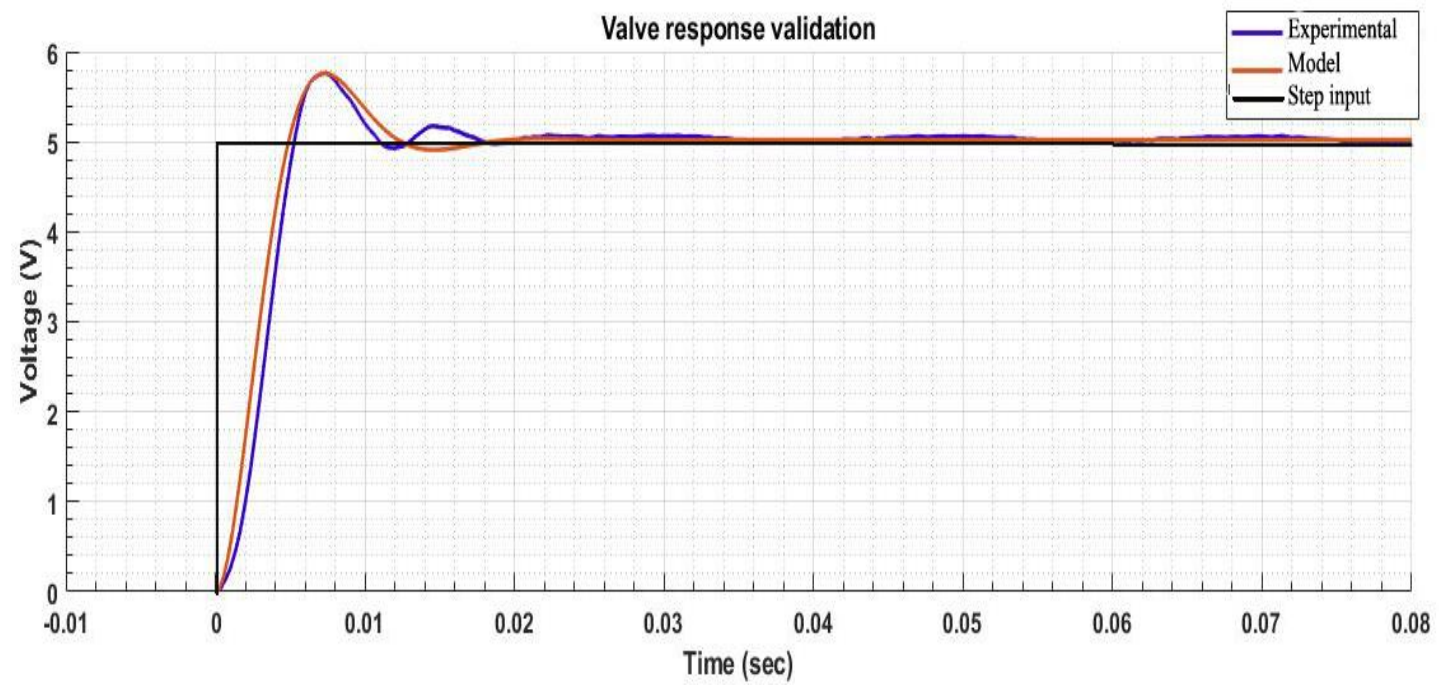

Figure 19. Valve response validation 
After giving the valve an input voltage, the spool moves. The total length of the spool stroke is small and found to be about $1 \mathrm{~mm}$ as seen from the manufacturer datasheet. Figure 20 represents the change of the valve opening area with the spool movement as described in Equations (7), (8) which is quite nonlinear.

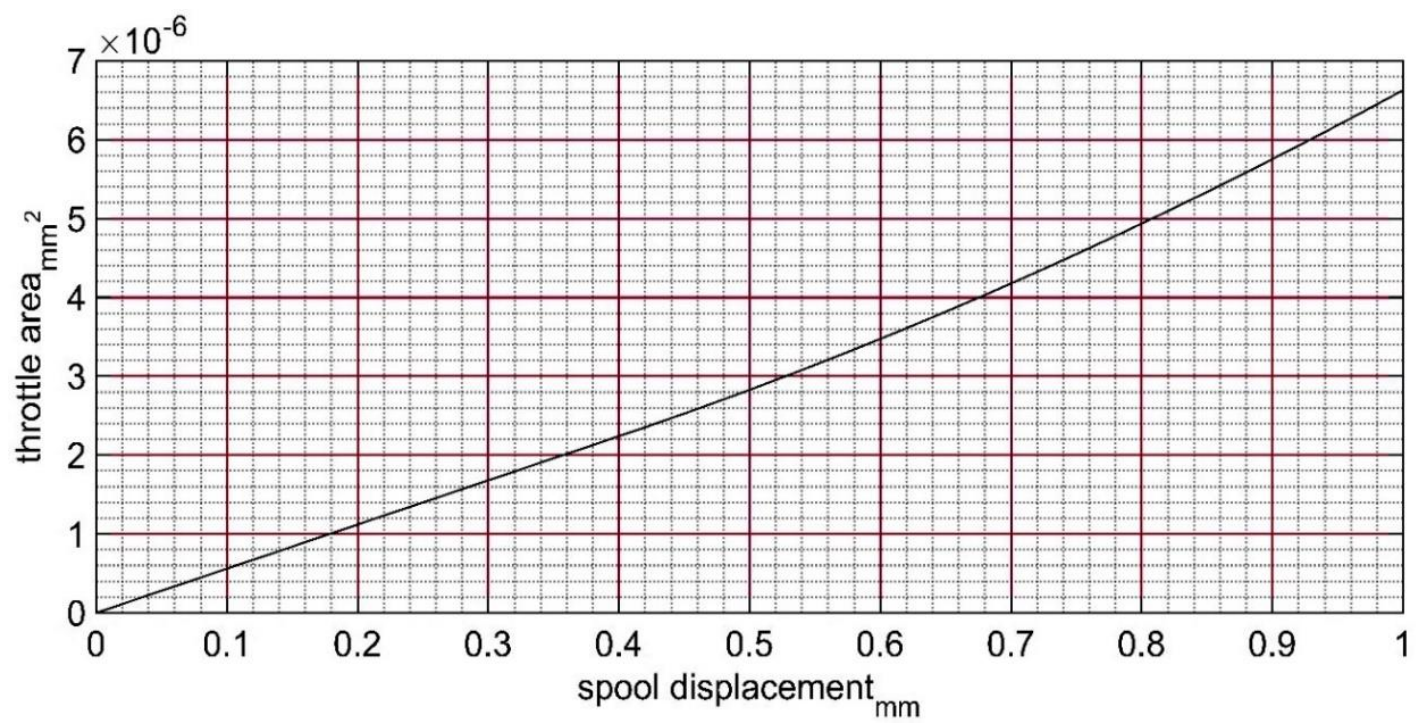

Figure 20. Throttling area $\left(\mathrm{mm}^{2}\right)$ versus spool displacement

Hydraulic cylinder transient response to a $50 \mathrm{~cm}$ step input displacement is being calculated using Simulink for an open-loop system. The results are plotted in Figure 21.

Figure 21 shows that the EHA presents an over-damped response to a step input that appears to be of the first-order system with a $200 \mathrm{~ms}$ time constant.

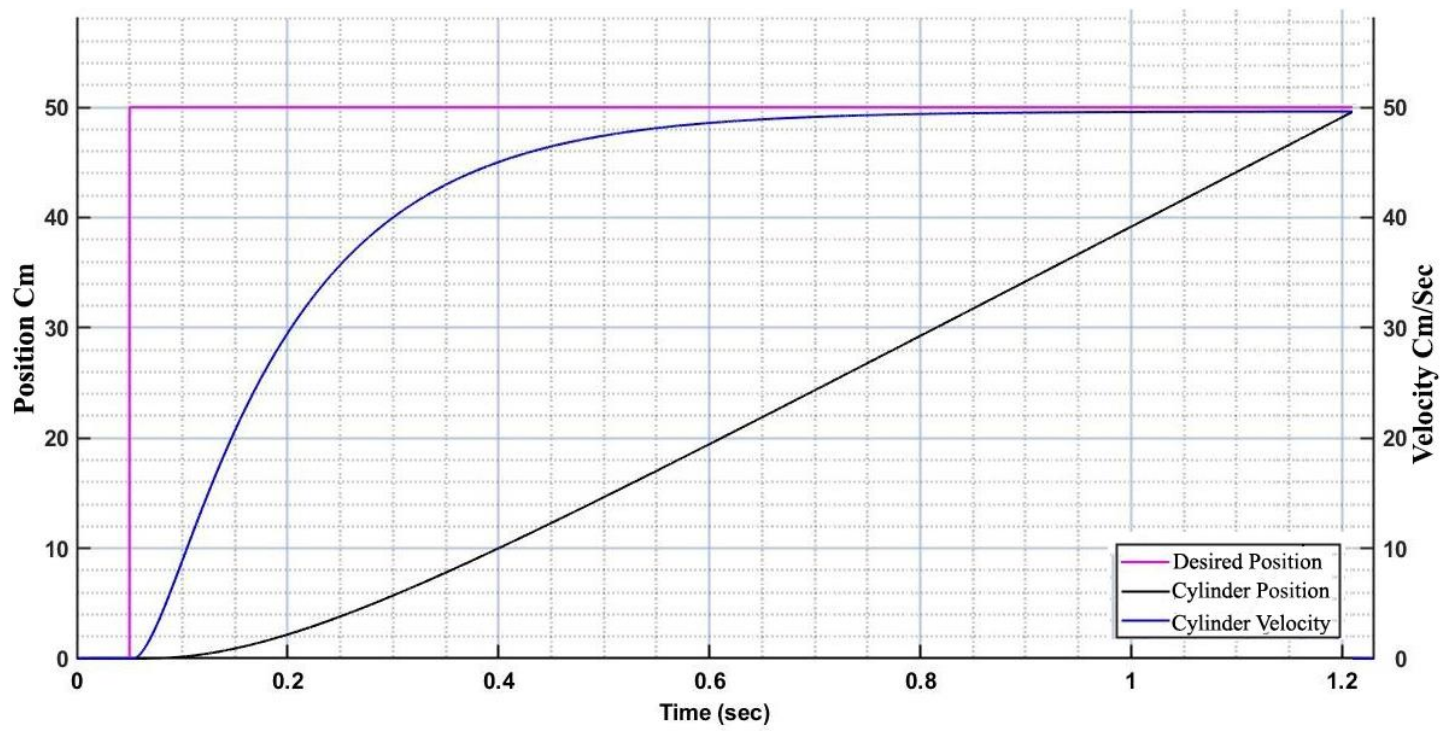

Figure 21. Model piston position, velocity, and desired input position.

The simulated model is being validated with experimental data which gives the same trend when giving a step input of $37 \mathrm{~cm}$ with an error of $1.35 \%$ of the final value as shown in Figure 22. Acceptable agreement between simulated and measured cylinder velocity is shown in Figure 23. 


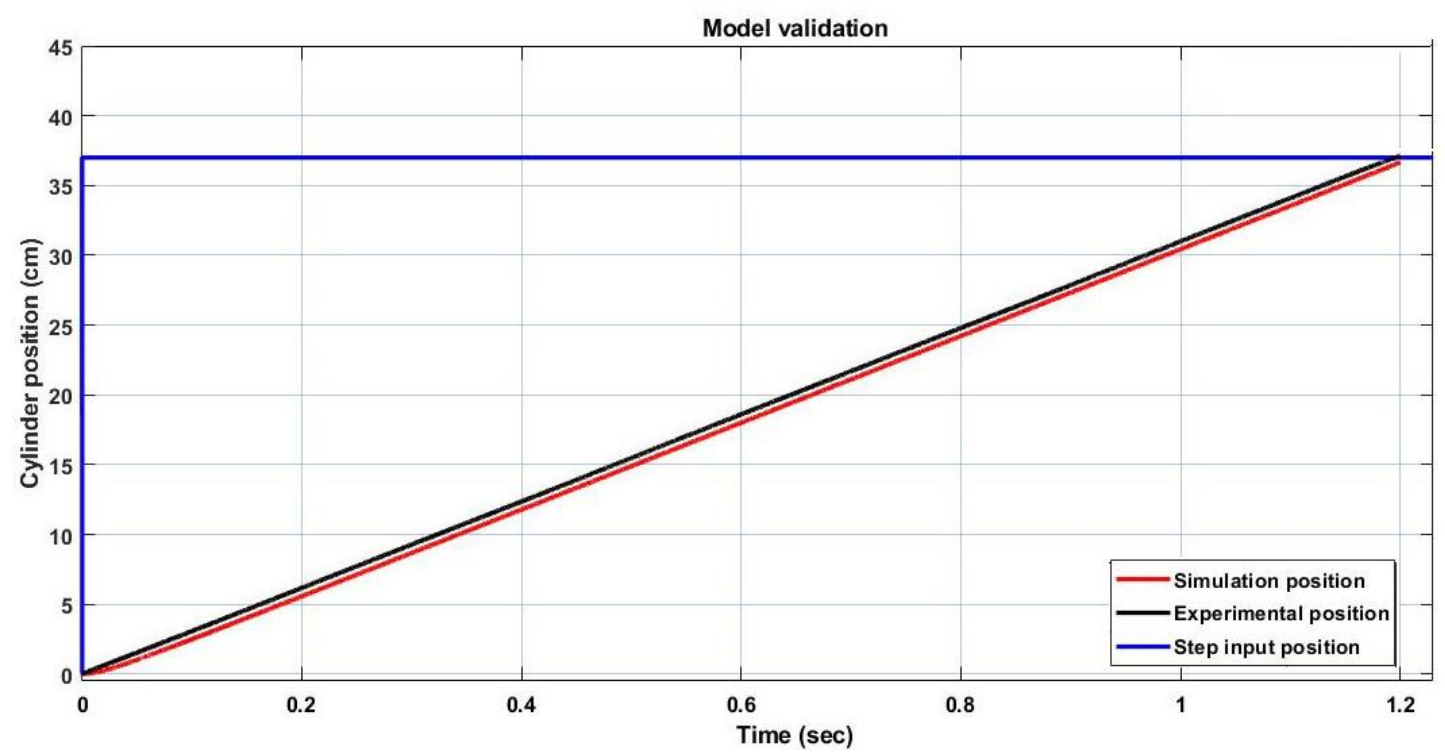

Figure 22. Validation of simulated and experimental cylinder position

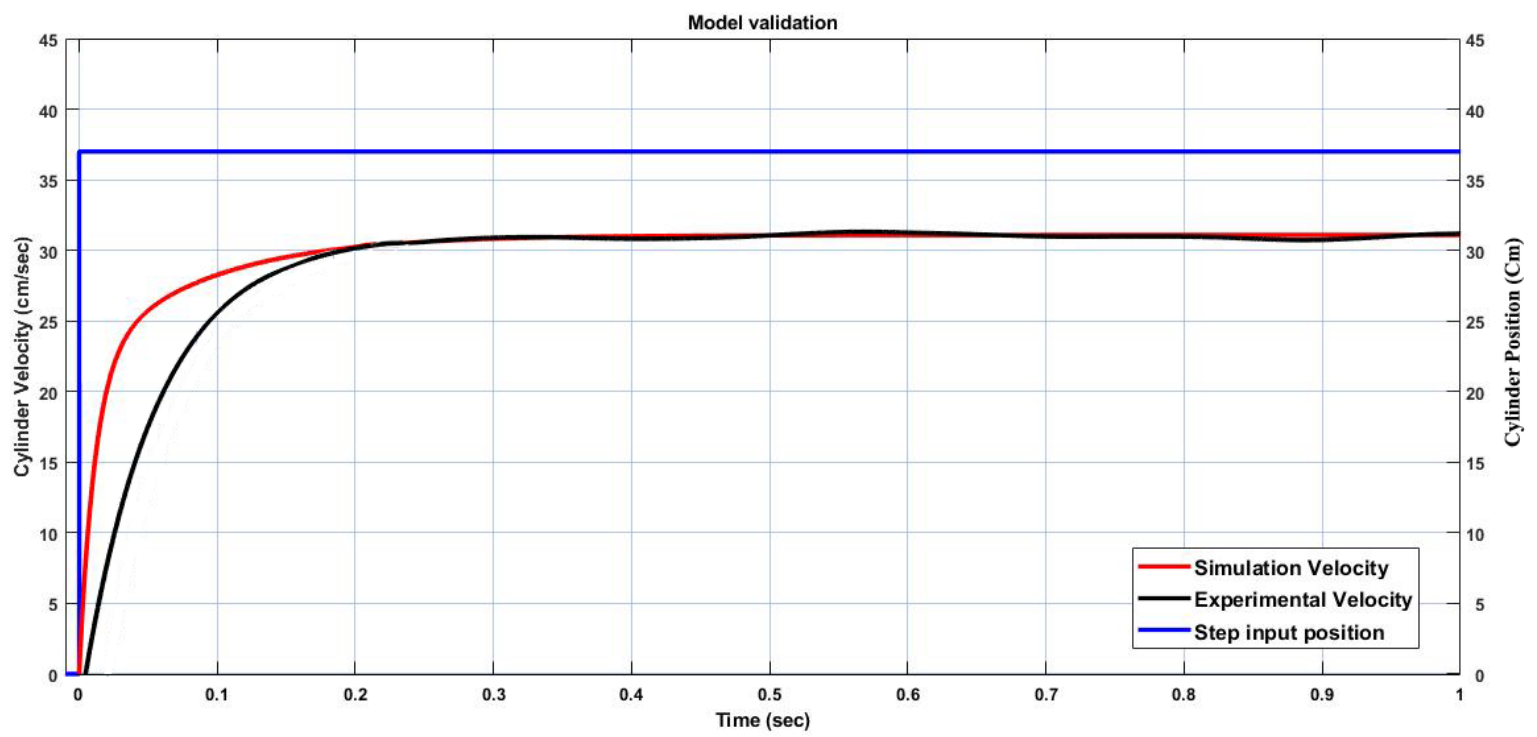

Figure 23. Validation of simulated and experimental cylinder velocity 


\section{Conclusion}

This paper fully describes a wave simulator that is used in PTO testing. The system's main feature is simulating real sea waves using a fast response proportional valve with a response time of $0.004 \mathrm{~s}$. A complete mathematical model has been obtained using MATLAB Simulink. However, the model developer had to find each hydraulic component parameters using the manufacturer datasheet. However, sometimes they are unavailable. The model considers the hydraulic oil losses in simulation. Besides, the developed model has been validated through the comparison between the experimental results of the real test bench and the simulation results. When the model cylinder position is being compared with the real cylinder position it gives the response with an error less than $5 \mathrm{~mm}$ for the open-loop system showing good correlations between the simulation model and experimental tests. Therefore, this model can be used to test Wave Energy Converters devices such as point absorbers and support the WEC testing and research community.

Application of PID controller on a closed-loop test rig reduces the tracking error of the measured cylinder position to be less than $2.25 \%$ of the desired position value which is acceptable.

As future work, the effect of the piston stick-slip needs to be studied. Also, the effect of the valve's delayed response on the actuator movement needs to be determined.

\section{References:}

[1] A. Clément et al., "Wave energy in Europe: Current status and perspectives," Renew. Sustain. Energy Rev., vol. 6, no. 5, pp. 405-431, 2002, doi: 10.1016/S1364-0321(02)00009-6.

[2] R. Ahamed, K. McKee, and I. Howard, "Advancements of wave energy converters based on power take off (PTO) systems: A review," Ocean Engineering, vol. 204. 2020, doi: 10.1016/j.oceaneng.2020.107248.

[3] B. Drew, A. R. Plummer, and M. N. Sahinkaya, "A review of wave energy converter technology," vol. 223, pp. 887-902, 2009, doi: 10.1243/09576509JPE782.

[4] IRENA, Renewable Energy Outlook: Egypt. 2018.

[5] A. Poullikkas, "Technology Prospects of Wave Power Systems," Electron. J. Energy Environ., no. JANUARY 2014, pp. 47-69, 2014, doi: 10.7770/ejeeV2N1-art662.

[6] B. Ayat, "Wave power atlas of Eastern Mediterranean and Aegean Seas," Energy, vol. 54, pp. 251-262, 2013, doi: 10.1016/j.energy.2013.02.060.

[7] M. A. Jusoh, M. Z. Ibrahim, M. Z. Daud, A. Albani, and Z. M. Yusop, "Hydraulic power take-off concepts for wave energy conversion system: a review," Energies, vol. 12, no. 23. MDPI AG, 2019, doi: 10.3390/en12234510.

[8] A. F. O. De Falcão, P. E. R. Pereira, J. C. C. Henriques, and L. M. C. Gato, 
"Hydrodynamic simulation of a floating wave energy converter by a U-tube rig for power take-off testing," Ocean Eng., vol. 37, no. 14-15, pp. 12531260, 2010, doi: 10.1016/j.oceaneng.2010.05.007.

[9] R. Henderson, "Design, simulation, and testing of a novel hydraulic power take-off system for the Pelamis wave energy converter," Renew. Energy, vol. 31, no. 2, pp. 271-283, 2006, doi: 10.1016/j.renene.2005.08.021.

[10] Z. Has et al., "Robust Position Tracking Control of an Electro-Hydraulic Actuator in the Presence of Friction and Internal Leakage," Arab. J. Sci. Eng., vol. 39, no. 4, pp. 2965-2978, 2014, doi: 10.1007/s13369-013-0888-3.

[11] N. D. Manring, L. Muhi, R. C. Fales, V. S. Mehta, J. Kuehn, and J. Peterson, "Using Feedback Linearization to Improve the Tracking Performance of a Linear Hydraulic-Actuator," J. Dyn. Syst. Meas. Control. Trans. ASME, vol. 140, no. 1, 2018, doi: 10.1115/1.4037285.

[12] R. Ghazali, Y. M. Sam, M. F. Rahmat, Zulfatman, and A. W. I. M. Hashim, "Simulation and experimental studies on perfect tracking optimal control of an electrohydraulic actuator system," J. Control Sci. Eng., vol. 2012, 2012, doi: $10.1155 / 2012 / 670635$.

[13] M. Jelali and A. Kroll, Hydraulic Servo-systems. 2012.

[14] M. Aly, M. Roman, M. Rabie, and S. Shaaban, "Observer-Based Optimal Position Control for Electrohydraulic Steer-by-Wire System Using Gray-Box System Identified Model," J. Dyn. Syst. Meas. Control. Trans. ASME, vol. 139, no. 12, Dec. 2017, doi: 10.1115/1.4037164.

[15] R. H. Bishop, The mechatronics handbook. 2002. 